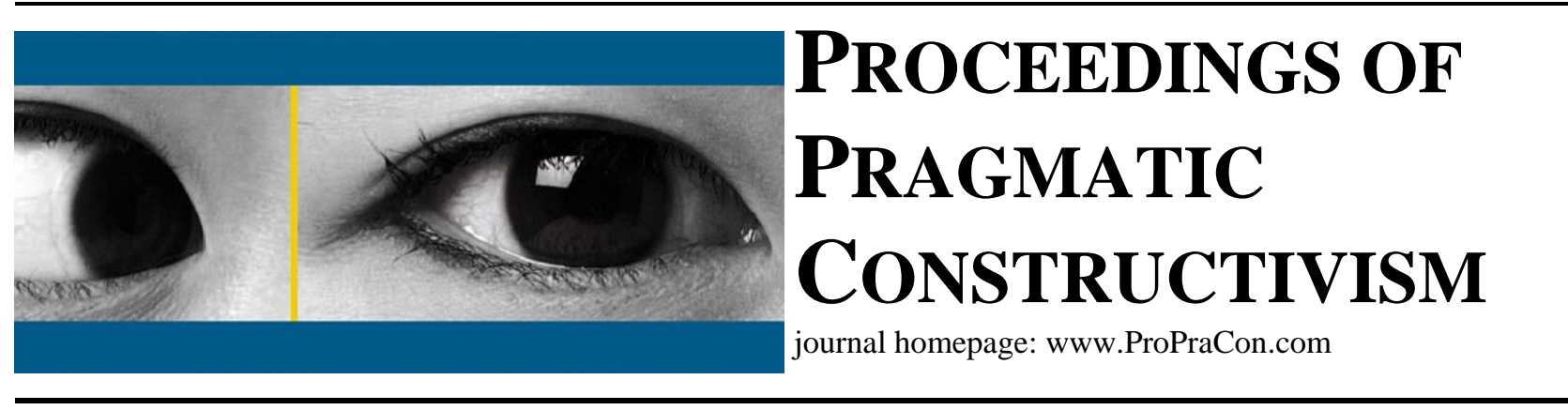

\title{
NPD accounting: unveiling the potential through pragmatic constructivism
}

\author{
Teemu Laine \\ Associate Professor \\ Tampere University of Technology; Cost Management Center \\ PO Box 541, 33101 Tampere, Finland; teemu.j.laine@tut.fi \\ Petri Suomala \\ Professor of Industrial Management \\ Tampere University of Technology; Cost Management Center \\ PO Box 541, 33101 Tampere, Finland; petri.suomala@tut.fi \\ Hanne Nørreklit \\ Professor of Management Control \\ Aarhus University; School of Business and Social Sciences; Department of Economics and Business \\ Fuglesangs Allé 4, 8210 Aarhus V, Denmark; $\underline{\text { hann@asb.dk }}$
}

\begin{abstract}
This paper examines the potential value of accounting for the NPD managers and argues that accounting information could play a more versatile role in supporting managerial work in NPD that has been reported. Besides providing facts, accounting may help managers identify their possibilities and communicate their values and valuations, which is to benefit the aims of product development process.

The paper draws from the idea that the roles of accounting vary under different types of uncertainties present in NPD processes. Especially, other roles than that of an "answer machine" are favored. To investigate this, the approach of pragmatic constructivism is employed, i.e., we analyze NPD accounting through facts, possibilities, values and communication related to NPD management. Empirically, the paper is based on 28 interviewees in 10 companies with significant NPD activities to explore the roles of NPD accounting and compare the potential value of accounting to the accounting employment of the examined companies.

From the perspective of pragmatic constructivism, the role of accounting should be clearly related to the analyses and communication of the possibilities and their values (ammunition device, learning device and rationalization device). If this was the case, accounting would be able to serve as an integrative device, which helps to identify (construct) causalities. However, the actual role given to accounting and identified by the managers is that of the provider of the seemingly objective economic facts (answer machine). Besides, the paper reports some best practices, where the managers either have started to actively identify learning opportunities from past projects through accounting information (“a learning theory of truth") or used accounting information from multiple viewpoints to systematically analyze and value the existing possibilities ("systematic construction of models").

Pragmatic constructivism provides a solid starting point for identifying the gaps in the management practice that could be fulfilled by accounting employment. Moreover, with the central concepts of the approach, potentially more valuable accounting roles could also be analytically constructed and communicated to the practitioners. Besides addressing the gap between the potential and actual roles of NPD accounting, the paper represents the few attempts to elaborate the accounting roles in systematic decision-making through pragmatic constructivism. Thus, the paper reflects more explicitly also upon seminal work on the roles of accounting in managerial decisions.
\end{abstract}

Keywords: new product development; pragmatic constructivism; accounting information. 


\section{Introduction}

This paper examines the role of accounting in NPD management with the help of the pragmatic constructivism paradigm (Nørreklit et al. 2006, 2010, Jakobsen et al. 2011). The theoretical tension underlying the paper is twofold. First, the actual practice of taking advantage of accounting information in decision-making and managerial work has received only a little attention (cf. Hall 2010), although the roles of accounting information in decision-making have been explored and examined quite extensively (Burchell et al. 1980, Hopwood 1980, Chapman 1997). Second, not much is known about how accounting information should be produced, disseminated, communicated and used in NPD management, given the fact that the role of accounting information in NPD is challenged by the contextual factors of NPD activities, such as the distinction between the content of the estimates and actual NPD activities (Nixon 1998, Jorgensen \& Messner 2010).

The employment of the pragmatic constructivism paradigm in this paper implies the operationalization of the concepts of fact, possibility, value and communication (Aristotle’s Metaphysics in Nørreklit et al. 2010). That is, the reality of an actor, who is in this paper either an accountant or a NPD manager, may be analyzed with the help of these concepts. We build on the idea that the reality that exists is a social reality, thus requiring communication between the actors and a shared view about the facts, possibilities and values. Moreover, as argued by Nørreklit et al. (2010), the employment of pragmatic constructivism enables examining the interplay between accounting and the socially constructed truth as well as approaching practices in an epistemologically objective manner, despite subjective, socially constructed world. Altogether, we seek to examine the practice of NPD accounting as it is constituted and viewed by the key actors in the NPD management, and thus to also systematically analyze the potential to enhance that practice. In this context, besides accounting logic, also technological logic and social logic have to be reflected upon to understand the potential of NPD accounting (Jakobsen et al. 2011).

We build also on Burchell et al. (1980), who proposed a wide research agenda to examine the roles of accounting in decision-making under uncertainty. In this vein, pragmatic constructivism provides a potentially useful structure for explicating the relationship between the actors' interpretations of the reality and the action taken by them jointly and individually. In particular, we acknowledge the potential of accounting under relatively high uncertainty in other roles that just the provider of economic facts, that is, the role of an "answer machine" in Burchell et al. (1980). First, if the relative uncertainty over the objective is low, but the uncertainty over the causes and effects of actions is high, accounting could be used as a "learning device” (Burchell et al. 1980, Chapman 1997), to gradually build understanding about the given phenomenon and to guide appropriate decisions. The learning theory of truth in pragmatic constructivism enables identifying such a role of accounting in building gradually better and more shared understanding about the business phenomena (Nørreklit et al. 2010, Mitchell et al. 2013). Second, if the relative uncertainty over the causes and effects is low, but there is high uncertainty over the objectives of the action, accounting should work as an "ammunition device", to provide different viewpoints to the decision-making situations (Burchell et al. 1980, Chapman 1997). In the wording of pragmatic constructivism, these different viewpoints provide information about the possibilities, and their (subjective) values will shape the decision-making (Nørreklit et al. 2010). Third, and finally, under relatively high uncertainty over both objectives and causes and effects, accounting may help in rationalization or provide inspiration (Burchell et al. 1980, Chapman 1997), thus making the socially constructed reality more clearly communicable for the actors.

Based on the existing literature, the reality of the actors in NPD management is not known to a sufficient degree, to actually describe in detail, how the production, dissemination, communication and use of accounting information take place in NPD. In fact, instead, an isolation between accounting and accountants and the NPD activities has been reported (see e.g., Rabino 2001) and there are also recent studies that strongly encourage to unveil the 'black-box' of NPD accounting (Jorgensen \& Messner 2010, Nixon et al. 2010, Nixon 1998). As NPD activities are essentially connected to the long-term planning of the companies, there is a clear need for accounting ex ante, e.g., product cost estimation, in addition to ex post measurement of e.g., NPD project costs (Davila \& Wouters 2007). However, as there is a distinction between the costs being estimated and the actions taken to affect those costs, there is a fundamental challenge in producing credible and useful accounting information. Jorgensen and Messner (2010) describe this dilemma as time-space difference between NPD activities and their outcomes. As a result, accounting information available for NPD management may not be sufficient for identifying and valuating all the relevant possibilities in a given decision-making situation, but actions need to be taken based on the overall awareness of single actor's reality or the socially constructed reality of all the relevant actors. In other words, decisions are made in the form of strategizing (Jorgensen \& Messner 2010), with a limited explicit use of accounting information, or they are made during the flow of events of the managerial work, based on the overall understanding of the business phenomena, and thus more implicitly affected by accounting figures (Hall 2010). Altogether, these challenges constitute a clear knowledge gap for better understanding the roles of accounting in supporting NPD management. 
Altogether, the paper examines the potential value of accounting for the NPD managers by arguing that accounting information could play such role in NPD decisions that is substantially greater than has so far been reported. Besides providing facts, accounting may help managers to identify their possibilities and communicate their values and valuations in different situations. The paper is based on the idea that multiple roles of accounting are favored in NPD decisions under different types of uncertainties. In particular, other roles than that of an "answer machine" can be encouraged (Burchell et al. 1980). In this paper, the approach of pragmatic constructivism is employed (Nørreklit et al. 2010), i.e., we analyze NPD accounting through facts, possibilities, values and communication related to NPD management to explore the current and potential roles of accounting information in NPD management. Instead of proposing general prescriptions for NPD accounting, the notion of construct causality (Jakobsen et al. 2011) is employed to understand the wider causalities in business underlying the NPD management and accounting enactment. Empirically, the paper is based on 28 interviews in 10 companies with significant NPD activities to explore the roles of NPD accounting and compare the potential value of accounting to the accounting employment of the examined companies.

The paper contributes to the NPD accounting literature by continuing to unveil the 'black-box' of NPD accounting, with the employment of pragmatic constructivism. It is argued that a constructive role of NPD accounting should be built on the analyses and communication of the possibilities and the underpinning values (ammunition device, learning device and rationalization device). Instead, the actual role given to accounting as identified by the managers is predominantly that of the provider of the seemingly objective economic facts (answer machine). However, the paper reports some best practices, where the managers either have started to actively identify learning opportunities from past projects through accounting information (“a learning theory of truth”) or used accounting information from multiple viewpoints to systematically analyze and value the existing possibilities ("systematic construction of models"). Besides addressing the gap between the potential and actual roles of NPD accounting, the paper represents a rare attempt to elaborate the accounting roles in systematic decision-making through pragmatic constructivism. Thus, the paper reflects more explicitly also upon seminal work on the roles of accounting in managerial decisions (Burchell et al. 1980). Altogether, pragmatic constructivism provides a solid starting point for identifying the gaps in the management practice that could be fulfilled by accounting employment. Moreover, with the central elements of the approach, potentially more valuable accounting roles could also be communicated to the practitioners.

The remainder of the paper is organized in the following way. The literature review deals with the uncharted roles of accounting in NPD management and provides an overview of the pragmatic constructivism as the analytical framework of the paper in justifying, defending and also extending practice. The empirical part of the paper provides an overview of the data, the results of the existing NPD accounting roles and enactments as well as elaborations on the 'best practice' and potential roles of accounting in NPD. The discussion section focuses on the gap between the theoretical and actual roles of accounting in NPD and the potential of extending the value of accounting practice, before the conclusion of the paper.

\section{Literature Review}

\subsection{Uncharted roles of accounting in NPD management}

Accounting for New Product Development (NPD) management has been examined in the accounting literature as a special case of accounting employment under remarkable uncertainty and with remarkable influence of the long-term profits of the company at hand. On one hand, in the literature, the focus has been on the adoption of NPD controls at the levels of portfolios and projects, when selecting and steering NPD activities of the companies (Cooper 1990, Davila 2000, Davila \& Wouters 2007, Davila et al. 2009a). On the other hand, the provision of accounting information in response to the challenging context of NPD has been examined in the literature (Nixon 1998, Davila \& Wouters 2007, Jorgensen \& Messner 2010), and the need for both quantitative and qualitative information (Nixon 1998), the requirements for both ex ante and ex post considerations (Davila \& Wouters 2007), and the existence of both 'accounting decisions' and 'strategizing decisions' (Jorgensen \& Messner 2010) have been discussed in the literature. However, the actual provision or development of accounting information or the actual roles given for accounting information have not been sufficiently addressed in the literature.

There are, as suggested in the literature, characteristics that challenge the existence of and the roles given to NPD accounting. An isolation between accounting and accountants and the NPD activities has been reported (see e.g., Rabino 2001). Moreover, there remains the fundamental challenge of combining control and creativity (Simons 1995) and accounting is still primarily considered as coercing creativity while aiming at controlling the business performance (see e.g., Davila et al. 2009b). However, there are case studies that have promoted the possibility to actually support NPD activities with accounting and control (Nixon 1998, Jorgensen \& Messner 2009), even if they at the same time 
echo the challenges of NPD as an accounting context and report context specific challenges in actually supporting NPD with accounting information. These include lack of top management commitment to developing NPD accounting sometimes (Jorgensen \& Messner 2009) and also the requirement of substantial, longitudinal approach in developing enabling accounting for NPD personnel.

In all, there are challenges in NPD context enactment that have limited the NPD accounting practice. The tension in this paper is the fact that the companies could still benefit significantly from an extended NPD accounting practice. The evidence for this proposition lies in only a few case studies, but it is still worth further examination. Firstly, Mouritsen et al. (2009) studied different forms of accounting information for innovation. They argued that the business phenomena may be transformed into accounting figures either as short translations with only few perspectives or as long translations that could capture the phenomenon from multiple perspectives. If long translations were used, as argued by Mouritsen et al. (2009), accounting could help not only in questioning and challenging the existing practices, but also eventually in extending the innovation activities of the companies. Therefore, the revision of the NPD accounting practice could also be favored. Secondly, Jorgensen and Messner (2009) used the distinction between enabling and coercive control (Ahrens \& Chapman 2004, Adler \& Borys 1996) and examined the possibilities for enabling roles of accounting information in the NPD context, thus supporting the managerial work of NPD personnel (cf. Hall 2010). As a result, a better balance between effectiveness and flexibility, or more broadly between innovation and control could be achieved through accounting development.

The roles of accounting and the possibilities of accounting development have not been studied embedded in the social context of NPD and by acknowledging the values and mindsets of NPD professionals, which nevertheless greatly affect the institutional role of accounting in product development. Therefore, exploration for better understanding current and potential NPD accounting practice seems clearly favorable.

\subsection{Pragmatic constructivism and the roles of accounting in NPD management}

In this paper, the pragmatic constructivism paradigm is employed as it is stated to be suitable for addressing business practices, in particular for justifying, defending and perhaps even extending those practices (Nørreklit et al. 2010, Jakobsen et al. 2011). Pragmatic constructivism is argued to be less reductionist than paradigms following the tradition of realism, thus allowing the co-existence of different socially constructed realities and different facts as understood by different actors (Nørreklit et al. 2010). The approach is therefore generally suitable for the exploration of the roles of NPD accounting that involves multiple decision makers and is essentially concerned with the evolving realities of the future businesses. In all, the pragmatic constructivism could add value to the NPD accounting literature, because it provides a potentially useful structure for the relationship between the actors' interpretations of the reality (business opportunities outlined by NPD activities) and the action taken jointly and individually by them (roles of accounting in NPD execution).

In the context of new product development, a shared understanding between key functions involved in NPD process on the realities can be considered as a prerequisite for making new products as factual possibilities (that is sellable products) for the developing firm. As Figure 1 below conveys, the construction of socially shared reality calls for exposure and integration between sets of values, local possibilities and factual observations that have remained partly or entirely separate within the organization. 
Figure 1: A schematic illustration of the cross-functional process of constructing integrated and shared reality in the context of product development.

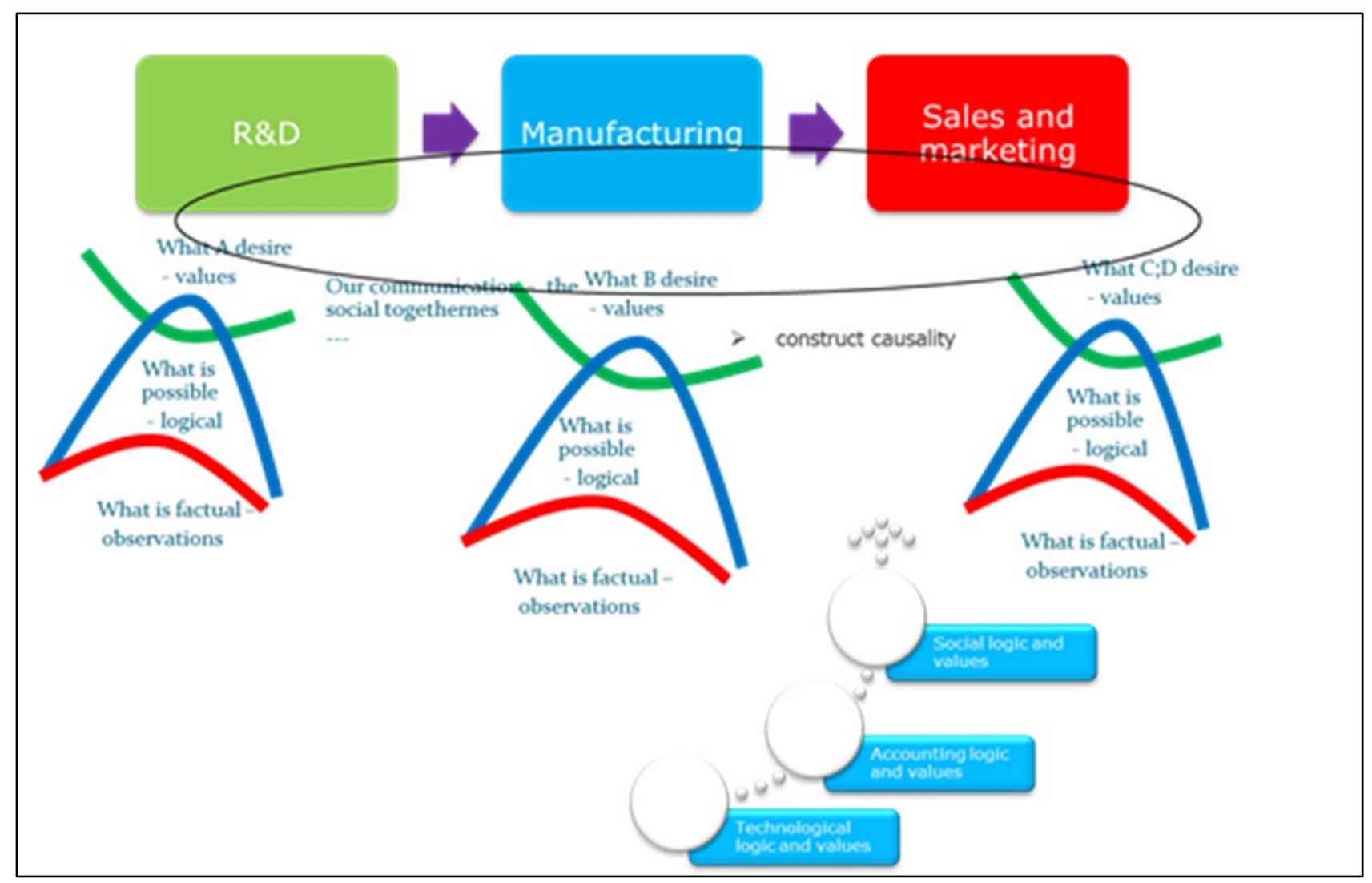

In this process both accounting logic, technological logic and social logic has to be aligned and critically reflected upon as the product development proceeds. In terms of accounting logic and values, the alignment means that accounting should be able to help individuals involved in the process to engage through accounting with technological and social challenges or obstacles that seem to hinder the accomplishment of development goals. How accounting in product development can be used in such a way that it would best support decision-making in the NPD process, is a key question here (Figure 1).

By the notion of construct causality we refer to an elemental and inherent aspect of all systems that involve human beings. As Nørreklit et al. (2012) points out: “...it is a myth that cause-and-effect relations in practice organizations are pre-existing, and waiting to be discovered. Cause-end-effect relations in practice are very complex constructions...” Thus 'construct causality' makes the study on the causes and effects in business quite interesting and constitutes a big difference between the 'systems of business' and 'the systems of nature'. Nørreklit et al. (2012) argue that: "In natural science, cause-and-effect relations are given by nature, so many feel tempted to search for general laws to identify causes in business in the belief that this is parallel to natural science. But that is a mistake. Business is based on "construct causality". Cause-and-effect relations are not given but are the result of social constructs in business ... By leaning to a vision that cause-and-effect in business is simply given by a sort of natural law, a myth is created. Such myth may lead managers and researchers to look for general laws to apply instead of applying and understanding the conditions for causes to work and business to function.” In our study, we analyze the potential of NPD accounting by acknowledging the construct causality in business and thus the need for a variety of different roles of accounting in the NPD activities.

The use of the pragmatic constructivism paradigm for exploring NPD accounting roles in this paper takes place in the following way. First, the central concepts of pragmatic constructivism, facts, possibilities, values and communication are presented in connection with NPD activities. Second, the potential roles of NPD accounting are further elaborated with the help of the seminal work on the roles of accounting in organizations (Burchell et al. 1980), thus outlining the potential roles of NPD accounting based on the conceptual analysis. After that, third, the current and potential roles of accounting in NPD are presented and discussed with the help of the interview data, which serves the basis for the conclusions of the paper. 
In pragmatic constructivism, the notions of facts, possibilities, values and communication represent as broad, yet structured starting point for examining business practice (Nørreklit et al. 2010). In general, there are number of facts that affect the individual actor's reality, by creating possibilities. The behavior of the actor is shaped by the value attached by the actor to those possibilities. An external observer may anticipate the individual actor's behavior, if the values are communicated by the actor, or if the observer knows already the patterns of behavior of the individual actor. In the business practice, there are multiple individual actors, who have their own realities shaped by the facts, possibilities and value and whose realities are bound together with communication, thus representing a socially constructed reality of a given company, business unit - or NPD organization. (Nørreklit et al. 2010)

In the NPD context, the facts can be related to the past or the present, regarding the execution of a given NPD project or the specifications, production volume and profit margin of the existing products. Essentially, there are also many factual possibilities in NPD, with a relatively high uncertainty, regarding the future; that is the specification of the forthcoming products and the estimates of the business consequences of them. Those lead into sound possibilities only if those facts with high uncertainty eventually hold true. However, there is uncertainty and concerns regarding all other facts as well, as they fundamentally are facts for the actors, as perceived by the actors, and therefore the estimates and other facts regarding the future business open possibilities similarly to the other types of facts. The challenge in the future business estimates lies in the communication of the facts, possibilities and values, as there is typically no sufficient ex post evidence regarding them and consensus about them may not be easily attained respectively.

As there are cultural barriers that hinder accountants' presence within the NPD activities (Rabino 2001), the translation of the facts regarding the future business into accounting figures may be undertaken by different actors (nonaccountants) within the NPD organization. As there multiple aims present simultaneously in many NPD projects (Davila \& Wouters 2007) the possibilities derived from the facts may be interpreted differently by different actors. Moreover, the values attached to the possibilities are continuously dependent on the actors' joint and individual interpretations and, thus, the decisions made regarding the NPD projects and future businesses more widely should be based on the continuously evolving facts, possibilities and valuations. This sets a fundamental challenge for providing suitable accounting information for NPD purposes, in a suitable form (Nixon 1998), to support the evolving decision making of the key actors in NPD organization (Jorgensen \& Messner 2010). Essentially, no process for accounting information provision could completely capture the challenge, outlined above, but, as argued in this paper, accounting information could still support the key actors, if desired information was available and if suitable roles were given to that information by those actors.

In order to examine the potential roles for accounting within NPD practice, we follow Burchell et al. (1980), who proposed already three decades ago a wide research agenda to examine the roles of accounting in decision-making under uncertainty. Especially, they emphasized the potential of accounting under relatively high uncertainty in other roles that just the provider of economic facts ("answer machine” in Burchell et al. 1980). In particular, if the relative uncertainty over the objective is low, but the uncertainty over causes and effects is high, accounting could be used as a "learning device" (Burchell et al. 1980, Chapman 1997), to gradually build understanding about the given phenomenon and its causes and effects. This idea is close related to the learning theory of truth in pragmatic constructivism (Nørreklit et al. 2010, Mitchell et al. 2013). In the NPD context, preliminary facts of the future businesses may be sharpened with a suitable accounting information provision, thus supporting learning among the key actors in NPD and thus better decisions made regarding the future businesses.

Moreover, following the proposed roles of accounting in decision-making (Burchell et al. 1980), if the relative uncertainty over the causes and effects is low, but there is high uncertainty over the objectives of the action, accounting should work as an "ammunition device", to provide different viewpoints to the decision-making situation (Burchell et al. 1980, Chapman 1997). In the wording of pragmatic constructivism, the different viewpoints provide information about the possibilities and their (subjective) values will shape the decision-making (Nørreklit et al. 2010). In NPD, especially, there is a need to integrate information from different sources (Wouters \& Roijmans 2011) or, in other words, use long translations (Mouritsen et al. 2009) to better understand the potential business consequences from multiple viewpoints, thus opening a clear potential for accounting in the NPD context. Finally, under relatively high uncertainty over both objectives and causes and effects, accounting may help in rationalization or provide inspiration (Burchell et al. 1980, Chapman 1997), thus making the socially constructed reality more clearly communicable for the actors. If nothing else, accounting information may provide one platform for communication for the NPD actors, as a 'language of business' (Avery 1952, see also Chapman 1997) and implicitly build a better understanding about the business phenomena influencing the NPD activities and the particular NPD projects at hand (Hall 2010). This role may also result in better decision-making as the uncertainties are lower in the future. 


\section{$3 \quad$ Empirical findings}

\subsection{Overview of the empirical data and analysis}

The paper reports results from an interview study conducted in ten industrial firms, in machinery manufacturing industry, and in representatives of other industries (ICT, information systems and consumer products). The companies are R\&D intensive companies in [a country] and within their industries. Some background information on Companies 1-10 is shown in Table 1.

Table 1: Background information on studied NPD organizations and the number of interviews.

\begin{tabular}{clccc}
\hline Company & Industry & $\begin{array}{c}\text { Nr of } \\
\text { employees }\end{array}$ & $\begin{array}{c}\text { Nr of interviews/ } \\
\text { interviewees }\end{array}$ & Duration \\
\hline 1 & Machinery manufacturing & $>5000$ & $3 / 5$ & $208 \mathrm{~min}$ \\
2 & Machinery manufacturing & $<5000$ & $3 / 3$ & $338 \mathrm{~min}$ \\
3 & Machinery manufacturing & $<5000$ & $1 / 3$ & $104 \mathrm{~min}$ \\
4 & Machinery manufacturing & $>5000$ & $1 / 1$ & $172 \mathrm{~min}$ \\
5 & Machinery manufacturing & $>5000$ & $4 / 5$ & $253 \mathrm{~min}$ \\
6 & Machinery manufacturing & $>5000$ & $2 / 3$ & $195 \mathrm{~min}$ \\
7 & Machinery manufacturing & $<5000$ & $3 / 3$ & $567 \mathrm{~min}$ \\
8 & ICT products and services & $>5000$ & $1 / 1$ & $76 \mathrm{~min}$ \\
9 & Consumer products & $<5000$ & $3 / 3$ & $502 \mathrm{~min}$ \\
10 & ICT products and services & $>5000$ & $1 / 1$ & $113 \mathrm{~min}$ \\
TOTAL & & & $22 / 28$ & $2529 \mathrm{~min}(42$ \\
& & & & $\mathrm{h} 9 \mathrm{~min})$ \\
\hline
\end{tabular}

The authors conducted and analyzed 22 in-depth interviews covering 28 persons in the companies. The interviewees represent different roles in NPD management: R\&D managers, project managers, marketing and product managers and business controllers. These roles are important in understanding the NPD accounting practice both from the viewpoint of accounting provision and the use of accounting in different types of managerial workflows. Thus, the presence of different types of actors in the empirical data helps us in building a more comprehensive view on the roles of accounting in NPD in general and in the studied organizations.

The overall theme of the interviews was the roles of accounting and control in NPD. The interviews were semistructured under four themes: 1) R\&D objectives, contents and focus areas, 2) Roles and contents of R\&D control and accounting, 3) R\&D measurement and financial control, 4) Accounting in different types of R\&D decision making contexts. The interview structure contained 24 questions regarding the topic(s), but the interview discussions were also influenced by the emerging topics brought up by the interviewees and, therefore, not all the questions were addressed in every interview. Regarding the empirical data of this paper, the most valuable data was collected under the themes 2 and 4 , but the material was analyzed completely to enhance the value of the data and cross-check the finding from different viewpoints.

The empirical data was structurally analyzed with the help of Atlas.ti program. The central concepts of pragmatic constructivism, facts, possibilities, values and communication (Nørreklit et al. 2010) were not explicitly used in the interview questions, but the connections to those concepts were established during the data analysis. To specify the roles of NPD accounting, the roles of "answer machine”, "ammunition device”, "learning device”, "inspiration device" and "rationalization device" (Burchell et al. 1980) were used to specify the actual roles of accounting information in different situations. The notion of "supporting managerial work" was used, if there was a more generic role of accounting information in a certain case. Moreover, there were a number of codes in use to highlight the actual managerial roles (e.g., project manager), the content of accounting (e.g., product cost) and the purpose of use of accounting information (e.g., ex post measurement), which specify more the context, where NPD accounting takes place.

\subsection{Overview of the empirical data and analysis}

In this section, the observed roles of NPD accounting are analyzed based on the interview data, to form the basis for the further analyses regarding the challenges and potential in NPD accounting enactment in the next section. In this section, 
we focus on the adoption of accounting and control tools, the primary content of accounting information and the roles given to it.

First, regarding the accounting and control tools, the studied organizations had (at least superficially) adopted NPD project models $(10 / 10)$ and R\&D portfolio management tools $(8 / 10)$, which is in line with the results regarding the adoption of NPD controls (see e.g., Davila et al. 2009a). If a R\&D portfolio management tool was defined more vaguely as a tool for selecting and managing NPD projects, such a tool was adopted by all the organizations under analysis.

The adoption of the portfolio tools and NPD project models had also influenced the respondent's views on the most important unit of analysis in the NPD management. In the interviews, the respondents were asked to choose the most important accounting object in NPD from project costs, product costs, project investment calculations and business impact analyses. Quite many managers highlight the business impact analyses and the product costs as the determinants of the projects' success. Quite often, the projects are assessed in light of the business impact and to be acceptable a project proposal needs to be written in the template in use in a given organization. As many companies represent machinery manufacturing characterized by remarkable cost competition, the NPD projects need to result in a product that meets the cost target set to it. However, some respondents questioned the ability of the organization to actually define, or refine the business impact analyses and cost targets set for the NPD projects. A project manager formulated the challenge in the following way:

\begin{abstract}
"At the moment, we do not re-visit the business impact analyses, but the newly nominated NPD director plans to now go through the earlier projects' BIAs and calculate them again with the actuals and current price levels to compare [estimates to actual figures].”
\end{abstract}

Moreover, there were also respondents who stated that the business controller function is interested merely on the R\&D costs and project budgets and the business impacts remain unaddressed after the choice of the projects to the portfolio.

The role of accounting information, highlighted by the respondents is more focused on the modelling and estimation of the business impacts than on the measurement of the actuals (as encouraged also in the review by Davila \& Wouters 2007). In Table 2, it is shown that the project and R\&D portfolio models require project budgets and also in most of the cases product cost targets and business impact calculations or investment proposals for the projects. As NPD activities intentionally shape the future business of the companies, the emphasis on the estimation if, of course, reasonable. However, more detailed analysis of the interviews reveals that ex post calculation takes place only rarely after the initial launch of the NPD project. In fact, only project costs are measured and systematically steered after the initial launch of the project. Besides, some companies revisit the product cost estimates and manage the product cost targets accordingly (3/10). In a small scale, this is done in the majority of the companies. (Occasional practice is phrased as "a little" in the table below.) What comes to the business impact analyses or the impacts assumed in the investment proposals, only rarely companies revisit those calculations or actively manage the projects according to the sharpening view on the business consequences.

Table 2: Purposes of use of different accounting objects in NPD.

\begin{tabular}{lllll}
\hline Company & Project cost & Product cost & Investment & $\begin{array}{c}\text { Business } \\
\text { Analyses (BIA) }\end{array}$ \\
\hline Modeling \& Estimation & $10 / 10$ & $9 / 10$, a little in 1 & $7 / 10$, a little in 1 & $9 / 10$ \\
Ex post calculation & $7 / 10$, a little in 3 & $3 / 10$, a little in 6 & $1 / 10$, a little in 2 & $0 / 10$, a little in 4. \\
\hline
\end{tabular}

In other words, it may be argued that the possibilities opened by the NPD projects are communicated in the beginning of the project, based on the facts that are prepared by the owners of the projects, typically product managers or project managers, but these possibilities are not re-thought after the acceptance of the project. However, the values attached to the possibilities are subject to change due to the major changes of the economic cycle, the dynamics of the markets of the products at hand and due to a number of other issues. Therefore, it could be assumed that the project execution could significantly benefit from an active steering of the business impacts. So far, the NPD accounting practice seemed well engaged only in the relatively traditional project control (e.g., the project budget) and in estimating/reviewing the product costs systematically in some organizations. However, the comprehensive financial impacts of the NPD projects were left unmanaged in majority of the studied organizations. 
One potential reason for the modest NPD accounting practice lies in the roles that are expected or given for accounting in NPD organizations at hand. The role of accounting information in the projects was explicitly asked from the respondents and the discussion about the roles was deepened in some cases also during the subsequent questions of the interviews. In all, according to the respondents, the role given to accounting is just the provision of economic facts, typically regarding the project and product costs (Burchell et al. 1980, Chapman 1997, Nørreklit et al. 2010).

If the NPD accounting practice was interpreted only through fact provision, the justification and value of the practice is merely based on the availability of (objective and correct) accounting information that informs the managers about the economics of a given accounting object. However, the multiple roles of accounting in supporting the managers have already been widely discussed and desired (Burchell et al. 1980, Chapman 1997, Jönsson 1998, Hall 2010, Nørreklit et al. 2010). In the NPD context, with a remarkable uncertainty stemming from the distance between actions and outcomes (Jorgensen \& Messner 2010), the desired roles of accounting are affected by the uncertainty as interpreted by individual managers.

When asked more about further and possibly emerging roles of accounting, most of the respondents referred to the potential of accounting that is not yet realized or to recent cases where accounting was used more than usually. As noted earlier, there were some companies that have begun to review the product cost estimates in the gates of the project model more systematically thus conveying an image of an active NPD accounting practice. Regarding the use of accounting as an "ammunition device" (Burchell et al. 1980, Chapman 1997), there were companies who did search for new pricing models for the products in some of the NPD projects. Moreover, there were best/worst scenarios included in the project selection of some companies, thus conveying the idea of multiple viewpoints to the business impacts of the projects. However, there were no signs of using accounting information for systematically scanning the different possibilities in terms of the business impacts of the projects, but the portfolio selection was made basically by using the project proposals as (socially constructed) sources of facts.

There were a couple of cases were NPD accounting can be interpreted as a "learning device” was (Burchell et al. 1980, Chapman 1997). There were situations, where the organization had learned to make better cost estimates for the NPD projects, after trial and error during the past projects. In other words, the facts in the past projects turned out to be erroneous and the assumptions underlying the product cost targets and cost estimation needed to be revisited. After a number of projects, sources of uncertainty in the cost estimates as well as the information needed for them were better known for the managers. Specific resources were thus allocated to the process of cost estimation. In one case, an idea of a NPD controller providing critique in the form of "lessons learned” report for the NPD project stakeholders was proposed. This idea was not yet in use, but it represents a possibility for enhancing the NPD accounting practice.

\subsection{Elaborating the challenges and potential value of NPD accounting}

Despite the existence of the NPD control tools, the roles given to NPD accounting reveal the challenge of actually support the NPD managers with accounting information. In sum, the roles of accounting are primarily those determined by the NPD project bureaucracy, but the more challenges calculations and analyses regarding the future possibilities remain typically unaddressed. This overall challenge was addressed by a product manager in the following way

”No patience enough [to make wise decisions]... In public companies, some managers think about next 5-10 years, and managers next door think about the ongoing 3 months."

As a result, the managerial workflows are overwhelmed by the timely issues and there seems to be not enough time to revisit or rethink the NPD activities and their meaningfulness within the organization. There are quite many managers, who therefore may just defend their own positions and do not actively explore new possibilities and communicate them.

Moreover, the recently adopted R\&D portfolio models do not seem to work according to the intention to support the work of the managers, but the administration routines are followed sometimes in a more coercive way. As business controller(s) brought up in one interview: just

\footnotetext{
"It seems that [odd] new projects just emerge, maybe they are approved by the steering group, I do not know"
}

From the viewpoint of the supply of the accounting information, the need for more actively manage the NPD projects and support the work of the managers with accounting information was identified by many. There was ere a R\&D director, who described their situation in the following way:

"[Recently] we have tried for the first time to develop new accounting information and base decisions on it... it has had a way too weak role earlier" 
In another company, the situation was described in a less positive way by the business controller(s):

"R\&D managers have given up, they do not ask [accounting information] anymore"

In all, the respondents acknowledged the remarkable challenge of actually supporting NPD projects with accounting information. The respondents in different positions agreed that as there are many competing requirements set for the NPD projects, the provision and active use of accounting information for NPD would need to take into account many different aspects. At the same time, there were only rarely specific resources allocated to NPD accounting, but the activities were taken by product managers (project proposals) project managers (operative project accounting) and business controllers (in different roles if available). The development of NPD accounting seemed to require extra attention and was observed in only few organizations.

\section{Discussion}

\subsection{Defending and extending the NPD accounting practice}

The challenges outlined by the interviewees thus shed light on the possibilities to justify, define and extend the NPD accounting practice. At the moment, the NPD accounting in the studied organizations is justified and defined based on the direct requirements of the NPD project models. As a result, the NPD accounting is focused on the formal requirements set for business impact analyses and investment proposals as well as the steering of the project costs during the project execution. In other words, the NPD accounting practice seems to be influenced by the idea of the general laws for NPD accounting and management that are responded to the design and implementation of formal NPD controls. At the same time the managers responsible for the NPD project execution are not actively supported in their work aiming at meeting the targets of the NPD projects, except for occasional product cost estimations. Arguably both accounting logic, technological logic and social logic should be aligned to better understand the construct causality of the NPD activities (Nørreklit et al. 2012). However, in the existing management practice, the integration of those logics is typically reduced to the employment of the NPD project model. As a result, NPD accounting is not given the roles related to critically examining the construct causality of the NPD processes, but NPD accounting more readily just provides economic facts according to the pre-defined project model. If the NPD accounting practice was defined based on the need for supporting the managerial work of the key stakeholders (Hall 2010), at least the following viewpoints may be highlighted by following the central concepts of the pragmatic constructivism:

Communication: Accounting information should help the NPD managers to communicate their reality with regard to the NPD project(s) at hand and thus formulate and continuously revisit the socially constructed reality with regard to the future product offering in the organization. For instance, the business impact analyses of the NPD projects could be continuously revisited and used (if needed) as communication platforms regarding the changes in the future product offering and its business consequences. Within the NPD organization, accounting could represent a common language (Avery 1952) for project managers and/or designers to assess or to propose changes regarding the NPD project execution. This is in line with the idea of Mouritsen et al. (2009) to use accounting for questioning, justifying and extending innovation activities in the companies, but we propose those activities to take place at multiple levels of the organizations.

Values: Accounting information should take into account multiple viewpoints to the values, primarily as the business potential(s) of the NPD project(s) at hand. If there are values per se, or personal values, within the NPD projects, these could be communicated among the managers, but perhaps separated from the economic values under analysis. The business controllers or project managers should be (if needed) able to provide information about the value of the product at hand, under different sets of assumptions and regarding different accounting objects (product, customer segment, business unit, company, personal values), thus influencing the decision-making. In all, long translations are desired in the NPD accounting with exploration involved (Mouritsen et al. 2009), at the same time allowing the existence of multiple viewpoints and socially constructed realities (Nørreklit et al. 2010).

Possibilities: As NPD activities hold significant uncertainty, there are also a number of possibilities regarding the business consequences of the NPD projects. There should be active processes of identifying new project idea, assessing the projects from multiple viewpoints and learning from the past projects also in terms of NPD accounting. The balance between flexibility and efficiency requires constant examination (Jorgensen \& Messner 2009) in the organization and individually to thus develop NPD management.

Facts: Actors choose and value the relevant facts in different ways and the socially constructed reality is the aggregation of those facts. The NPD accounting system should acknowledge the existence of different types of projects and related facts and, therefore, the NPD accounting should not be limited to the information available in the accounting 
information system or required by the project model. The desired accounting tools could be developed also informally through accounting prototypes (as proposed by Wouters \& Roijmans 2011) and in the long term, the most appropriate tools are adopted for wider used within the NPD organization. In all, the realities and the economic facts as interpreted by key NPD managers require continuous attention to enable learning and further development of NPD accounting (Ahrens \& Chapman 2007: continuously redefining accounting practice).

\subsection{Assessing pragmatic constructivism in addressing NPD accounting practice}

The paper is stated, first, to contribute to the NPD accounting literature by making an attempt to open the 'black-box' of NPD accounting (cf. Nixon 1998, Jorgensen \& Messner 2010), with the employment of pragmatic constructivism. It is argued that the role of NPD accounting should be clearly related to the analyses and communication of the possibilities and their values (ammunition device, learning device and rationalization device) (Nørreklit et al., see also Burchell et al. 1980). However, the actual role given to accounting as identified by the managers is that of the provider of the seemingly objective economic facts (answer machine) (ibid). In all, it was observed that a less reductionist approach, such as pragmatic constructivism, that allows the interpretations of the multiple actors' viewpoints through their 'own' realities, and the idea of the construct causality, provided a sound starting point for exploring NPD accounting practice (in line with Nørreklit et al. 2010). As a result, not only the limitations of the calculations or the accounting and control systems, but also a set of other challenges were observed to hinder the value of NPD accounting. Moreover, despite the seemingly successful adoption of the NPD project models in the examined companies, the examination went beyond the formal accounting process to the wider roles given to accounting and the challenges stemming from the demanding managerial workflows (Hall 2010).

With the help of a more detailed examination of the central concepts of pragmatic constructivism, the paper reports some best practices, where the managers either have started to actively identify learning opportunities from past projects through accounting information (“a learning device in Burchell et al. 1980, "a learning theory of truth” in pragmatic constructivism) or used accounting information from multiple viewpoints to systematically analyze and value the existing possibilities ("ammunition machine” in Burchell et al. 1980, "long translation in Mouritsen et al. 2009, "systematic construction of models" in pragmatic constructivism). Besides addressing the gap between the potential and actual roles of NPD accounting, the paper represents the few attempts to elaborate the accounting roles in systematic decision-making through pragmatic constructivism. Thus, the paper reflects more explicitly also upon seminal work on the roles of accounting in managerial decisions (Burchell et al. 1980) in light of the more recent streams of accounting literature.

\section{Conclusion}

Practically relevant accounting research requires in-depth understanding of the accounting practice. So far NPD represents one of the least understood practices from accounting viewpoint. This paper employs pragmatic constructivism approach to extend our understanding about the roles of accounting in NPD to partially respond to the outlined gap in the literature. As a result, there is ample scope of further examining NPD accounting practice to realize the value attached to the accounting possibilities in the NPD organizations.

From the perspective of pragmatic constructivism, the role of accounting should be clearly related to the analyses and communication of the possibilities and their values (ammunition device, learning device and rationalization device). If this was the case, accounting would be able to serve as an integrative device, which helps to identify (construct) causalities. In the NPD accounting context, that is so far characterized with a lack of accounting support for the key managerial roles, there would be a need for exploration of potential accounting roles and contents. In the long term, the accounting development may yield an appropriate NPD accounting practice that acknowledges the existence of the construct causality in the business context (Nørreklit et al. 2010, Jakobsen et al. 2011) and enables continuous reconstitution of the desired NPD accounting practice (Ahrens \& Chapman 2007). In all, pragmatic constructivism provides a solid starting point for identifying the gaps in the management practice that could be fulfilled by accounting employment. Moreover, with the central concepts of the approach, potentially more valuable accounting roles could also be analytically constructed and communicated to the practitioners.

The research process underlying this paper benefitted from the employment of pragmatic constructivism. However, the paper is not to say that the approach is under any circumstances better than another theory for studying practice. Instead, the fragmented findings regarding NPD accounting practice (and accounting practice in general) should talk to each other to enable triangulation and eventually a comprehensive understanding about the value drivers in using accounting for different managerial purposes. 


\section{References}

Adler, P. S., Borys, B. 1996. Two types of bureaucracy: enabling and coercive. Administrative Science Quarterly, 41(1), 61-89.

Ahrens, T., Chapman, C.S. 2004. Accounting for flexibility and efficiency: a field study of management control systems in a restaurant chain. Contemporary Accounting Research, 21(2), 271-301.

Ahrens, T., Chapman, C. 2007. Management accounting as practice. Accounting, Organizations and Society, 32(1/2), $1-27$.

Avery, H. G. (1952). Accounting as a Language. The Accounting Review. 28(1), 83-87.

Burchell, S., Clubb, C., Hopwood, A., Hughes, J., Nahapiet, J. 1980. The roles of accounting in organizations and society. Accounting, Organizations and Society, 5(1), 5-27.

Cooper, R. G. 1990. Stage-gate systems: A new tool for managing new products. Business Horizons, 33(3), 44-54.

Davila, T. 2000. An empirical study on the drivers of management control systems' design in new product development. Accounting, Organizations and Society, 25(4), 383-409.

Davila, T., Wouters, M. 2007. Management accounting in the manufacturing sector: managing costs at the design and production stages. In: Chapman, C.S., Hopwood A.G., \& Shields, M. (Eds.), Handbook of Management Accounting Research. Elsevier, Amsterdam: 831-858.

Davila, T., Foster, G., Li, M. 2009a. Reasons for management control systems adoption: Insights from product development systems choice by early-stage entrepreneurial companies. Accounting, Organizations and Society, 34(2), 322-347.

Davila, A., Foster, G., Oyon, D. 2009b Accounting and control, entrepreneurship and innovation: venturing into new research opportunities, European Accounting Review, 18(2), 281-311.

Hall, M. 2010. Accounting information and managerial work. Accounting, Organizations and Society, 35(3), $301-315$.

Hopwood, A. G. 1980. Organizational and behavioural aspects of budgeting and control, in Arnold, J., Carsberg, B., Scapens, R. (Eds) Topics in Management Accounting. Oxford: Philip Allan Publishers.

Jakobsen, M., Johansson, I-L. and Nørreklit, H. (Eds.) 2011. An Actor's Approach to Management. Conceptual framework and company practices. Copenhagen: DJØF Publishing.

Jönsson, S. 1998. Relate management accounting research to managerial work! Accounting, Organizations and Society, 23(4), 411-434.

Jørgensen, B., Messner, M. 2009. Management control in New Product Development: thedDynamics of managing flexibility and efficiency. Journal of Management Accounting Research, 21(1), 99-124.

Jørgensen, B., Messner, M. 2010. Accounting and strategizing: A case study from new product development. Accounting, Organizations and Society, 35(2), 184-204.

Mitchell, F. Nielsen, L. B., Nørreklit, H., Nørreklit, L. 2013. Scoring strategic performance: a pragmatic constructivist approach to strategic performance measurement. Journal of Management and Governance, 17(1), 5-34

Mouritsen, J., Hansen, A., and Hansen, C. 2009. Short and long translations: management accounting calculations and innovation management. Accounting, Organizations and Society, 34(6), 738-754.

Nixon, B. 1998. Research and development performance measurement: a case study. Management Accounting Research, 9(3), 329-355.

Nixon, B., Burns, J., Jazayeri, M. 2010. The Role of Management Accounting in New Product Design and Development. Interdisciplinary Research in Cost, Profitability and Performance Management in Manufacturing, Logistics and Service Operations, Ghent: June 20-23, 2010.

Nørreklit, L., Nørreklit, H., Israelsen, P. 2006. The validity of management control topoi: towards constructivist pragmatism. Management Accounting Research, 17(1), 42-71.

Nørreklit, H., Nørreklit, L., Mitchell, F. 2010. Towards a paradigmatic foundation for accounting practice. Accounting, Auditing \& Accountability Journal, 23(6), 733-758.

Nørreklit, H., Nørreklit, L., Mitchell, F., Bjørnenak, T. 2012. The rise of the balanced scorecard! Relevance regained? Journal of Accounting \& Organizational Change, 8(4), 490-510

Rabino, S. 2001. The accountant's contribution to product development teams and a case study. Journal of Engineering and Technology Management, 18(1), 73-90.

Simons, R. 1995. Levers of Control. Boston, MA: Harvard Business School Press.

Wouters, M., Roijmans, D. 2011. Using prototypes to induce experimentation and knowledge integration in the development of enabling accounting information, Contemporary Accounting Research, 28(2), 708-736. 